\title{
Scripted communication for service standardisation? what analysis of conversation can tell us about the fast-food service encounter
}

\begin{abstract}
In highly routinised service encounter interactions, communication is often guided by service scripts that are the material embodiment of institutional expectations of how the service interaction is to be conducted. However, counter to common belief that scripted communication is well-controlled and homogeneous in its execution, observation of actual talk reveals interesting patterns and variations that reflect the ways in which participants make meaning of and perform their respective roles within the interaction towards achieving the overall goal of the service communication. Applying the analysis of speech functions and sequential order of talk in audio-recorded verbal exchanges between servers and customers at the service counter of a fast-food restaurant, acts in the fast-food service interaction are interpreted and explained in relation to management-prescribed service script, servers' scriptin-use and customers' script within an institutional discourse framework. Findings from the study have important implications for service management and training as it addresses the tension between the practices on the ground and those sanctioned by the organisation.
\end{abstract}

Keyword: Business communication; Conversation analysis; Customers' script; Discourse in organisations; Fast-food service; Institutional discourse; Scripted communication; Service encounter; Service training 